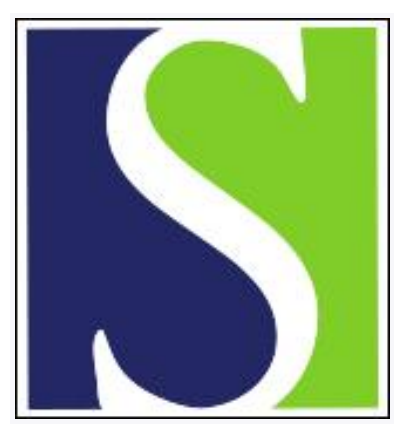

Scand J Work Environ Health 1981;7(1):8-13

https://doi.org/10.5271/sjweh.2563

Issue date: Mar 1981

Methyl chloride and diazepam effects on performance.

by Putz-Anderson V, Setzer JV, Croxton JS, Phipps FC

Key terms: alertness; behavioral test; diazepam; diazepam effect; methyl chloride; methyl chloride effect; performance; toxicology

This article in PubMed: www.ncbi.nlm.nih.gov/pubmed/7313613 


\title{
Methyl chloride and diazepam effects on performance
}

\author{
by Vernon Putz-Anderson, PhD, James V Setzer, BSc, Jack S Croxton, PhD, \\ Frederick C Phipps, BSc ${ }^{1}$
}

\begin{abstract}
PUTZ-ANDERSON V, SETZER JV, CROXTON JS, PHIPPS FC. Methyl chloride and diazepam effects on permormance. Scand $j$ work environ health 7 (1981) 8-13. Human behavioral effects resulting from the ingestion of an average dose of diazepam and from $3 \mathrm{~h}$ of inhaling either $100 \mathrm{ppm}$ or $200 \mathrm{ppm}$ of methyl chloride (MeCl) were studied in the laboratory. Each of 56 volunteers was randomly assigned to one of six groups comprising the combinations of diazepam and placebo and one of the two leveils of $\mathrm{MeCl}$ plus control. Each individual was tested in an environmental room on three tasks involving components of eye-hand coordination, mental alertness, and time discrimination. Both pretreatment and treatment data were obtained. Diazepam produced a significant $10 \%$ impairment in task performance, whereas the effect of 200 ppm of $\mathrm{MeCl}$ was marginally significant (average performance impairment of $4.5 \%$ ). When the two agents were combined, total impairment was equal to the sum of the individually induced losses. Large interindividual differences in breath and blood levels were found for $\mathrm{MeCl}$.
\end{abstract}

Key terms: alertness, benavioral tests, diazepam, toxicology.

Repko and his associates (9) found that, when compared with slightly younger controls, workers exposed to approximately $43 \mathrm{ppm}$ of methyl chloride $(\mathrm{MeCl})$ vapor exhibited increased tremor and impaired performance on cognitive time-sharing tasks. By comparison, Stewart et al (10) found no consistent behavioral effects on four subjects during a controlled laboratory exposure to $100 \mathrm{ppm}$ of $\mathrm{MeCl}$ for $7.5 \mathrm{~h}$.

Methyl chloride $\left(\mathrm{CH}_{3} \mathrm{Cl}\right)$ is a widely used and a relatively nontoxic chlorinated hydrocarbon at low exposure levels (4). Over 293,000 metric tons of this industrial solvent are used annually in the rubber,

1 Division of Biomedical and Behavioral Science, National Institute for Occupational Safety and Health, Cincinnati, Ohio, United States.

Reprint requests to: Dr V Putz-Anderson, Robert A Taft Laboratories, National Institute for Occupational Safety and Health, $4676 \mathrm{Co}-$ lumbia Parkway, Cincinnati, OH 45226, USA. plastics, petroleum, and stainless steel industries (13). The current US standard of the Occupational Safety and Health Administration (OSHA) specifies that levels of $\mathrm{MeCl}$ are not to exceed a time-weighted average (TWA) of $100 \mathrm{ppm}$ during an 8-h day, or a ceiling concentration of $200 \mathrm{ppm}$ (14).

The nervous system appears to be the prime target for $\mathrm{MeCl}$ toxicity (4). According to Eckardt (1) the effects of excess exposure to $\mathrm{MeCl}$ on humans are similar to that of alcoholic intoxication. The symptoms include ataxic gait, nervousness and emotional instability, lack of limb coordination, headache, and drowsiness. These effects may be aggravated in workers who are being treated simultaneously with a central nervous system depressant such as diazepam (Valium ${ }^{\circledR}$ ).

The following study was designed to assess the potential behavioral effects, on humans, of an acute exposure at permissible levels to the solvent vapor of $\mathrm{MeCl}$ 
by itself and in combination with an average dose of diazepam. Because of the known depressant or narcotic action of both chemicals, it was hypothesized that the inhalation of $\mathrm{MeCl}$, alone or in combination with the consumption of diazepam, would impair performance on tasks that require alertness. Moreover, the combined effect would at least be equal to the sum of the independent effects, ie, the effect would be additive.

\section{Subjects and methods}

\section{Subjects and experimental design}

Fifty-six participants, of whom 17 were females, were recruited from neighboring universities over a three-month period and given physical examinations. The participants, whose ages ranged from 18 to 32 a (mean 22 a), were assigned to one of six groups comprising a $3 \times 2$ factorial design. The first factor $(\mathrm{MeCl})$ consisted of the following three levels or concentrations $0,100,200 \mathrm{ppm}$, whereas the second factor consisted of a placebo capsule $(0 \mathrm{mg})$ and a 10-mg diazepam capsule. Four groups had 12 participants, and two groups, those exposed to the 100-ppm concentration, had eight participants, four who also received a placebo capsule and four who received the diazepam dose.

\section{Procedures}

Each participant was tested repeatedly for alertness during $5 \mathrm{~h}$ of testing. Three different behavioral tests were used to obtain a total of 20 measures for each individual. Ten measures were accumulated during the 2-h pretreatment period, and a second set of 10 measures was obtained during the 3-h treatment period. In addition alveolar breath samples were collected every hour. Venous blood samples were obtained prior to exposure and approximately $90 \mathrm{~min}$ after exposure commenced. Procedures dealing with the analyses of the breath and blood samples followed the methods developed by Stewart et al $(10,11)$ and Hake et al (3). So that simultaneous peak body burdens would be attained for $\mathrm{MeCl}$ and diazepam during the behavioral test phase of the treatment schedule, the diazepam capsule was administered to each participant 30 min prior to the beginning of the $\mathrm{MeCl}$ exposure.

Data analyses were performed with multivariate techniques. A $5 \%$ significance criterion was chosen; the average test power was 0.70 . The behavioral data from the eight participants exposed to 100 ppm of $\mathrm{MeCl}$ were not included in the statistical analyses because of the small number of participants, the expected low effect level, and the desire to maintain statistical power. Hence the statistical design for the analyses of the behavioral data reverted to a $2 \times 2$ factorial. However, exposure-induced body-burden data from the 100-ppm treatment have been provided. For descriptive purposes, a percentage change $(\% \mathrm{C})$ statistic was computed for each variable in the following manner: the raw score (amount impairment), obtained during the pretreatment period, was subtracted from the score obtained during the treatment period and the result was divided by the score obtained during the pretreatment period.

All procedures were in accordance with the guidelines of the Human Subject Review Board of the National Institute for Occupational Safety and Health (NIOSH). The study was conducted as a single blind one. Each volunteer was requested to abstain from the use of caffeine, alcohol, or any medication for $24 \mathrm{~h}$ prior to the experiment. Only professed nonusers of diazepam were allowed to participate.

Participant pairs were tested in a controlled-environment room with an inside dimension of approximately $2 \mathrm{~m}^{3}$. Each participant sat in a chair at a desk in front of a remote computer-controlled cathode ray tube (CRT). Pure $\mathrm{MeCl}$ was administered from a pressurized cyclinder through an inlet port of the environmental room and recirculated in a semiopen system. Since $\mathrm{MeCl}$ is odorless at low levels, no masking of the exposure concentration was necessary. Room concentrations were measured by an infrared spectrophotmeter and a gas chromatograph with an integrator. [For the method used, see Hake et al (3) and Stewart et al (10)].

\section{Performance tests}

The tests consisted of three tasks, visual vigilance, dual task, and time discrimina- 
tion, which were presented and controlled by a PDP-12 computer. All three tasks were designed to assess different aspects of human attention or alertness, and they were adaptive in that signal conspicuity was performance-adjusted to maintain a stable criterion. Stability was achieved by the automatic increasing or decreasing of the level of the task load (input) to correspond to the operator's performance (12). Hence, 80 to $90 \%$ of the measured variance on a given trial was a response to the optimum level of the task load introduced during a given experimental condition. The label "threshold performance level" (TPL) was given to the quantitative measure of that point on the continuum of task loads at which performance levels approached $70 \%$ accuracy. The remaining 10 to $20 \%$ of the measured variance was assessed by two additional indices: response time (RT) and number of response blocks. [A response block (RB) is a longer than usual RT, ie, an RT which exceeds the mean plus two SDs of the baseline data.] The participants were trained for approximately $70 \mathrm{~min}$ until their performance levels stabilized. Both pretreatment and treatment scores were obtained from the counterbalanced administration of the three tests.

Visual-vigilance task. The visual-vigilance task resembled an automated version of Mackworth's Clock Test (5) with a CRT display $(8,12)$. Once every second a light dot $(0.2 \mathrm{~cm}$ in diameter) "jumped" a standard distance of $5 \mathrm{~cm}$ away from the center of the display (velocity $=40 \mathrm{~cm} / \mathrm{s}$ ), paused for $0.35 \mathrm{~s}$, and then returned to the center for $0.35 \mathrm{~s}$. At random times (range 10-170 s, mean $90 \mathrm{~s}$ ) the length of the "jump" was increased or decreased by $\mathrm{X}$ times delta. Delta was set at 1.5 times the individual's threshold on the task, as established during training, or at about $6.5 \mathrm{~mm}$. The value of $X$ was set between 1 and 8 by a titration process. As with the Clock Test, the signal was a jump longer in length than the standard, and it required a button-push response. However, in the present adaptive version, the distance that the signal jumped was dependent on the success or failure associated with the occurrence of the two previous signals. For example, after two successive correct detections $\mathrm{X}$ was increased by 1 unit and multiplied by delta; at the next occurrence of a signal the distance of the jump was decreased by the preceding value to approach the standard jump length, ie, it became more difficult. An increase in the distance of the signal jump - beyond the $5-\mathrm{cm}$ standard - occurred following two errors in detection. The TPL scores represented the average distance the signal jumped throughout the test period with a $70 \%$ performance accuracy.

Dual task. Tone detection and eye-hand compensatory tracking comprised the two test components of the dual task (8). A low intensity tone $(65 \mathrm{~dB}, 750 \mathrm{~Hz})$ was presented briefly $(250 \mathrm{~ms})$ through a lightweight headphone set. A silent interval of $750 \mathrm{~ms}$ followed the tone. The sequence was repeated every second for the duration of the 25-min test period. At random times a tone slightly higher in pitch was presented $(A \mathrm{~F}=4 \mathrm{~Hz})$. On the average it occurred once every $25 \mathrm{~s}$ (32 times/test) and served as the signal. The conspicuity of the signal in the self-adaptive test was varied through the adjustment of the frequency of the signal tone in increments of $4 \mathrm{~Hz}$ above the reference tone of 750 $\mathrm{Hz}$. The computer used the same algorithm as was used in the previous test for determining the magnitude of the signal. The required response to a signal was a button push. Average TPL, RT, and RB scores were obtained for each participant.

The second component of the dual task, performed in conjunction with the tone task, consisted of compensatory tracking. The participant viewed two arrows in the middle of a CRT; one pointed down (target) and was stationary, and the other pointed up (cursor). The latter oscillated horizontally in response to a semirandom, sinusodial forcing function of $5 \mathrm{c} / \mathrm{min}$. By applying light horizontal pressure to a control lever (Measurement Systems, model 435), mounted in front of the CRT, the participant attempted to align the cursor with the stationary arrow. The tracking activity (TA) scores represented the average amount of error or deviation between the target and cursor.

Time discrimination task. In the time-discrimination task a sequence of 1-s tone bursts $(68 \mathrm{~dB}, 850 \mathrm{~Hz})$ interspersed with a 
2-s off-time was presented to each participant through a headphone set. The task was to push a button in response to a signal, which was a tone burst longer in duration than the standard $1-s$ burst. The signal occurred on the average of once every $48 \mathrm{~s}$ throughout the 25 -min test; it was presented randomly. Adaptive techniques based on the same algorithm as in the first test were employed to determine the conspicuity of the signal. The time differences were based on increments of $100 \mathrm{~ms}$. The TPL score represented the smallest time difference detected between the signal and the standard (1-s) tone with $70 \%$ accuracy. In addition to the TPL score, both RT and number of RBs were also measured.

\section{Results}

\section{Exposure/biochemical data}

The desired exposure level of either 200 ppm or $100 \mathrm{ppm}$ was reached for the respective groups within the first $30 \mathrm{~min}$ after exposure began and was maintained (SD $4.5 \mathrm{ppm}$ ) throughout the $3-\mathrm{h}$ exposure period. The participants were no more successful than chance in guessing which $\mathrm{MeCl}$ concentration they had been exposed to. However, because of the noticeable relaxing effect of diazepam, $65 \%$ of the participants correctly identified the treatment.

Breath levels of the participants reached equilibrium within the first hour of exposure. For the 24 individuals exposed to $200 \mathrm{ppm}$ of $\mathrm{MeCl}$, the average breath level was $63 \mathrm{ppm}$ (SD $23.6 \mathrm{ppm}$ ); the breath levels for the eight individuals exposed to $100 \mathrm{ppm} \mathrm{MeCl}$ averaged $36 \mathrm{ppm}$ (SD $12 \mathrm{ppm})$, or 30 to $40 \%$ of the exposure level. The standard deviations amounted to 37 and $33 \%$ of the respective mean values. A closer inspection indicated that 3 of the 24 participants exposed to 200 ppm of $\mathrm{MeCl}$ had breath levels in excess of $100 \mathrm{ppm}$ or $50 \%$ of the exposure level, whereas the majority of participants had lower levels. As expected, the blood and breath levels were highly correlated $(\mathrm{r}=0.85, \mathrm{~N}=29, \mathrm{p}<0.01)$. For the 200 ppm exposed group, the average blood concentration was $11.5 \mathrm{ppm}$ (SD $12.3 \mathrm{ppm}$ ), whereas an average blood concentration of $7.7 \mathrm{ppm}$ (SD $6.3 \mathrm{ppm}$ ) was registered for those individuals exposed to $100 \mathrm{ppm}$ of $\mathrm{MeCl}$. For the 28 participants who received $10 \mathrm{mg}$ of diazepam, the blood concentration averaged $290 \mathrm{ng} / \mathrm{ml}$ (SD $87 \mathrm{ng} / \mathrm{ml}$ ), a level at the high end of the normal therapeutic range.

Performance changes during exposure. The results of the multivariate analysis of variance (MANOVA) indicated that the diazepam treatment was significant at the $1 \%$ level $[\mathrm{F}(10,35)=6.1$, Wilk's $\psi=$ $0.36]$; the $\mathrm{MeCl}$ treatment approached significance at the $5 \%$ level $[\mathrm{p}<0.053, \mathrm{~F}(10$, $35)=2.09$, Wilk's $\psi=0.62]$. No significant interaction was found between the $\mathrm{MeCl}$ exposure and diazepam treatment $[\mathrm{F}(10$, $35)=0.45$, Wilk's $\psi=0.88$ ]. In the followup unvariate analyses, only the TPL vigilance test score and $R B$ measure of time discrimination were sensitive indicators of $\mathrm{MeCl}$ impairment. In contrast, the diazepam treatment, which proved to be dominant, had a significant effect on all test indices, except the RB measure of time discrimination.

Table 1. Degree of impairment on behavioral tests expressed as the percentage of change $(\% \mathrm{C})$ between pretreatment and the subsequent test period during the methyl chloride (MeCl) and diazepam study. (TPL = threshold performance level, $\mathrm{RT}=$ reaction time, $\mathrm{RB}=$ response block, $\mathrm{TA}=$ tracking activity, $-=$ impairment, $+=$ improvement)

\begin{tabular}{|c|c|c|c|c|c|c|c|c|c|c|c|c|}
\hline \multirow{2}{*}{\multicolumn{2}{|c|}{ Condition }} & \multicolumn{10}{|c|}{ Test } & \multirow{3}{*}{$\begin{array}{l}\text { Mean } \\
(\% \mathrm{C})\end{array}$} \\
\hline & & \multicolumn{3}{|c|}{ Visual vigilance } & \multicolumn{4}{|c|}{ Dual task } & \multicolumn{3}{|c|}{$\begin{array}{c}\text { Time-discrimi- } \\
\text { nation }\end{array}$} & \\
\hline $\begin{array}{l}\mathrm{MeCl} \\
(\mathrm{ppm})\end{array}$ & $\begin{array}{l}\text { Diazepam } \\
\text { (mg) }\end{array}$ & TPL & RT & $\mathrm{RB}$ & TPL & RT & RB & TA & TPL & RT & RB & \\
\hline 0 & 0 & -1.3 & -7.2 & -4.7 & -0.1 . & -5.5 & -7.6 & -14.4 & +1.1 & +6.5 & +5.9 & -2.73 \\
\hline 0 & 10 & -3.6 & -18.8 & -8.2 & -9.8 & -17.0 & -12.6 & -36.5 & -9.3 & -14.6 & +1.8 & -12.8 \\
\hline 200 & 0 & -4.7 & -10.3 & -6.4 & -3.1 & -7.1 & -6.5 & -11.5 & -5.0 & -3.8 & -8.3 & -6.7 \\
\hline 200 & 10 & -12.1 & -20.4 & -9.6 & -10.0 & -23.6 & -20.7 & -32.1 & -8.4 & -15.3 & -9.5 & -16.2 \\
\hline
\end{tabular}


The degree of impairment for each of the dependent measures is shown in table 1. The control group (row 1) showed an average decline of $2.73 \%$ in performance between the precontrol and control test periods. The diazepam treatment (row 2) showed an average impairment of $12.8 \%$ from the pretreatment to the treatment period. When the aforementioned control effect was removed (fatigue, etc), the net decline was $10.1 \%$. The average impairment found with the $\mathrm{MeCl}$ treatment (row 3 ) was $6.7 \%$, or a net decline of $4 \%$. The combined treatment of $\mathrm{MeCl}$ and diazepam (row 4) produced an average impairment of $16.2 \%$, or a net decline of $13.5 \%$.

\section{Discussion}

The main finding indicates that exposure to $200 \mathrm{ppm}$ of $\mathrm{MeCl}$ for $3 \mathrm{~h}$ had little or no effect on the three tests of alertness. However, an average dose of diazepam resulted in an overall performance impairment of $10 \%$. When $\mathrm{MeCl}$ was combined with diazepam, the degree of impairment was essentially equivalent to the sum of the effects that occurred individually with each agent; hence, no potentiation was found.

The present results are in close agreement with the findings from Stewart's laboratory $(3,10)$. They examined the behavioral and neurological effects of repeated exposures to a maximum of 150 ppm of $\mathrm{MeCl}$. With one exception, they found no deleterious behavioral or neurological effects from $\mathrm{MeCl}$ exposure. In their study, a small impairment was observed on a time-discrimination test involving a light stimulus. In the present investigation, a small impairment was also found on a time-discrimination task (RB measure) involving an auditory stimulus.

As was the case in the present study, Stewart et al (10) and Hake et al (3) noted an unusually high level of variance associated with the mean body-burden measures of the groups exposed to $\mathrm{MeCl}$. They found that 4 of the approximately 20 subjects had much higher alveolar breath and blood concentrations of $\mathrm{MeCl}$ than their peers after identical exposures. As in the present study, no direct explanation for the effect was apparent.
In a study of chemical workers exposed to $\mathrm{MeCl}$ in a manufacturing plant, Repko et al (9) found behavioral impairments associated with chronic $\mathrm{MeCl}$ exposure that averaged $34 \mathrm{ppm}$. The impairments were not correlated with $\mathrm{MeCl}$ breath levels. When compared with younger controls, the chemical workers exhibited increased tremor and impaired performance on a time-sharing task. The task comprised three separate watchkeeping activities, as well as performance on an intermittent one- or two-digit arithmetic test. By comparison, the time-sharing task in the present study consisted of a dual arrangement with a continuous tracking task and tone monitoring activity. The latter task was also moderately effective in differentiating between the control and $\mathrm{MeCl}$-exposed individuals. Although the overall effects due to $\mathrm{MeCl}$ exposure were small in both studies, the data support the notion advanced by Putz (7) that multiple tasks with high-demand characteristics are sensitive indicators of toxic stress.

The significant effect of diazepam on the behavioral tests of alertness was not unexpected. Numerous investigators have found similar results in laboratory situations $(2,6)$. However, as with most drugs that influence behavior, the effects of the drug are difficult to separate from the mood or personality of the recipient. An even more critical influence is the situational context of drug administration, ie, whether the individual requires the drug. It is our experience that most research volunteers are normal, confident and relatively low in anxiety and hence do not need the drug to relax any further. In a relatively nonstressful experiment involving long and repetitious tasks that require alertness, the effects of such a drug are likely to impair normal performance, as was observed in the present study. However, when the drug is given for therapeutic reasons, the effects on performance may be quite different.

The findings of the present study also correspond to the results obtained by Stewart et al (11) in a laboratory investigation of perchloroethylene, diazepam and ethanol. Both diazepam and ethanol produced significant impairments on a battery of behavioral tests, which included eye-hand coordination, rotary pursuit, and a dual task. As a result of exposure to 100 
ppm of perchloroethylene for $5.5 \mathrm{~h}$, a small impairment in performance was detected on a coordination test. However, as was the case in the present study with $\mathrm{MeCl}$, the real effect, if any, was small. Again, no interaction was found between the solvent and either of the two drugs. Nevertheless, both Stewart's result and the findings of the present study serve to emphasize the potential hazard stemming from the combined effects of central nervous system depressants on workers engaged in activities requiring alertness and coordination.

\section{Conclusion}

Under the conditions studied, 3-h exposure to $\mathrm{MeCl}$ at $200 \mathrm{ppm}$, a level equivalent to the current US standard of a TWA of $100 \mathrm{ppm}$, resulted in little or no behavioral impairment. By comparison, diazepam produced a significant loss of $10 \%$ on the attention tasks. The combined diazepam/solvent treatment failed to support an interacting or potentiating effect. The total assessed impairment in performance was essentially equal to the sum of the losses observed for the individual agents, ie, the effect was additive. Finally, there were large interindividual differences in the $\mathrm{MeCl}$ concentration of both alveolar air and venous blood at the same exposure level. Additional studies linking exposure concentration, uptake, and the associated biological reactions are necessary.

\section{Acknowledgments}

The following individuals contributed significantly to the outcome of the study: BJ Taylor; L Hatch, DO, PhD; HB Plotnick, $\mathrm{PhD}$; BL Johnson, $\mathrm{PhD}$; WK Anger, $\mathrm{PhD}$; and N Dickerson.

\section{References}

1. Eckardt RE. Industrial intoxications which may stimulate ethyl alcohol intake. Ind med surg 40 (1971) 30-35.

2. Haffner JF, Morland J, Setekleiv J, Strom- saether CE, Danielsen A, Frivik PT, Dybing F. Mental and psychomotor effects of diazepam and ethanol. Acta pharmacol toxicol 32 (1973) 161-178.

3. Hake CL, Stewart RD, Wu A, Forster HV, Newton PE. Experimental human exposures to methyl chloride at industrial environment levels. Paper 160 presented at the Sixteenth Annual Meeting of the Society of Toxicology, March 27-30, 1977.

4. Irish DD. Halogenated hydrocarbons: I. Aliphatic. In: Patty FA, ed. Industrial hygiene and toxicology. 2nd ed. John Wiley \& Sons, New Yonk, NY 1963, pp 1241-1332.

5. Mackworth NH. Researches on the measurement of human performance. In: Sinaiko HW, ed. Selected papers on human factors in the design and use of control systems. Dover Publications, New York, NY 1961, pp 174-331.

6. Morland J, Setekleiv J, Haffner JF, Stromsaether CF, Danielsen A, Holst Wether G Combined effects of diazepam and ethanol on mental and psychomotor functions. Acta Pharmacol Toxicol 34 (1974) 5-15.

7. Putz VR. The effects of carbon monoxide on dual-task performance. Hum factors 21 (1979): 1, 13-24.

8. Putz VR, Setzer JV, Croxton JC, Phipps FC. Effects of acute low level methyl chloride exposure combined with diazepam on behavioral and neurological measures of human activation levels. Paper presented at the 87th Annual Convention of the American Psychological Association. New York, NY, Sept. 3, 1979.

9. Repko JD, Jones PD, Garcia LS, Schneider EJ, Roseman E, Corum CR. Final report of the behavioral and neurological evaluation of workers exposed to industrial solvents: Methyl chloride. University of Louisville, Louisville, KY 1976. (Performance research laboratory report, 1976. Contract no. CDC 99-74-20).

10. Stewart RD, Hake CL, Wu A, Graff SA, Forster HV, Keeler WH, Lebrun AJ, Newton PE, Soto RJ. Methyl chloride: Development of a biologic standard for the industrial worker by breath analysis. National Institute for Occupational Safety and Health, Cincinnati, OH 1977. (Report no NIOSH-MCOW-ENVM-MCM-77-1).

11. Stewart RD, Hake CL, Wu A, Kalbfleisch $J$, Newton PE, Marlow SK, Vucicevic-Salama M. Effects of perchloroethylene/drug interactions on behavior and neurological function. National Institute for Occupational Safety and Health, Cincinnati, OH 1977. (Report no DHEW (NIOSH) 77-191).

12. Wiener EL. Adaptive measurement of vigilance decrement. Ergonomics 16 (1973): 4, $353-363$.

13. Chemical profile: Methyl chloride. Chemical marketing reporter 1973.

14. Code of federal regulations. 29 CFR 1910.1000, table Z-2.

Received for publication: 30 May 1980 